Historic, archived document

Do not assume content reflects current scientific knowledge, policies, or practices. 



\section{SOUTHERN FOREST EXPERIMENT STATION}

E. L. Demmon, Director

New Orleans, La.

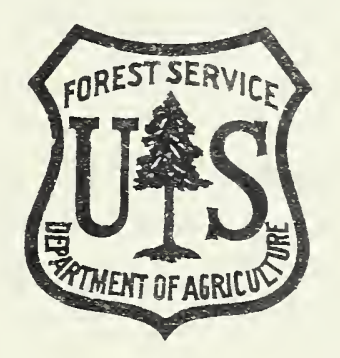

MECHANICAL ADVANCES AT THE STUART FOREST NURSERY

By

1. A. Huberman, Junior Forester,

Southern Forest Experiment Station.

* This series of publications releases data gathered in connection with investigations being carried on at the Southern Station. The information contained in them is subject to correction or amplification following further investigation. - Editor 



\author{
By \\ M. A. Huberman, Junior Forester, \\ Southern Forest Experiment Station. \\ I. Longleaf Seeder
}

Sowing seed for an annual production of 50 million trees presents a task of sizeable proportions. To sow this seed in the shortest possible time renders this task somewhat of a problem.

In the 1934 season the Stuart Forest Nursery, on the Kisatchie National Forest, La., had a scheduled production of 12 million trees. Of this, five million were to be longleaf, five million slash, and two million shortleaf pine. Sowing the slash and shortleaf seed was easily accomplished by the use of the Hazard drill seeder, which was designed by J. O. Hazard of Tennessee to sow locust seed. This machine, a modification of a grain drill, operates on the principle of small geared wheels at the bottom of a seed box feeding the smooth seed into tubes of spring steel, through which the seed is dropped on the ground in drills.

THE HAZARD SEEDER CANNOT BE USED TO SOW LONGLEAF PINE SEED, because the seed wings of this species, which cannot be removed like those of slash and shortleaf pine, clog the geared wheel-feeds. Hence in 1934 it was necessary to sow the longleaf seed by hand.

Because of the anticipated increase in production for 1935 and ensuing seasons, and because of the time factor in sowing and the greater ease of weeding and lifting in drills as compared with broadcast-sown beds, it was decided to design some sort of longeaf drill seeder. Therefore, the Stuart Nursery staff, consisting at that time of Nurseryman J. T. May, L. R. Holdridge, J. Williamson, and the author, conferred and began to outline various ideas for sowing longleaf seed in drills. These ideas were based chiefly on placing the seeds in drills across the beds rather than along the beds as is done by the Hazard seeder. After numerous sketches and a few parts of models has been made up, J. Williamson suggested the use of carpenter's drill bits allowed to turn in a funnel to feed the longleaf seed from a seed box into tubes, and thus to sow the seed in drills running the long way of the bed. The idea was found to be a good one, and Williamson made up partial models and tried feeding seeds through such an arrangement. The size and pitch of the bit and the rate at which the bit was revolved determined the amount of seed fed through the funnel. The next step was to build a full-size model and try it out. This involved an arrangement of gears which had to be computed carefully.

A seed box was built of wood with 8 square funnels at the bottom, set six inches apart. (See figures 1 and 2.) In each of these funnels a drill bit, fastened to a shaft, was placed. To each shaft a beveled gear was fastened, resting on a bar across the top of the seed box in a horizontal position. A horizontal shaf $t$ above 


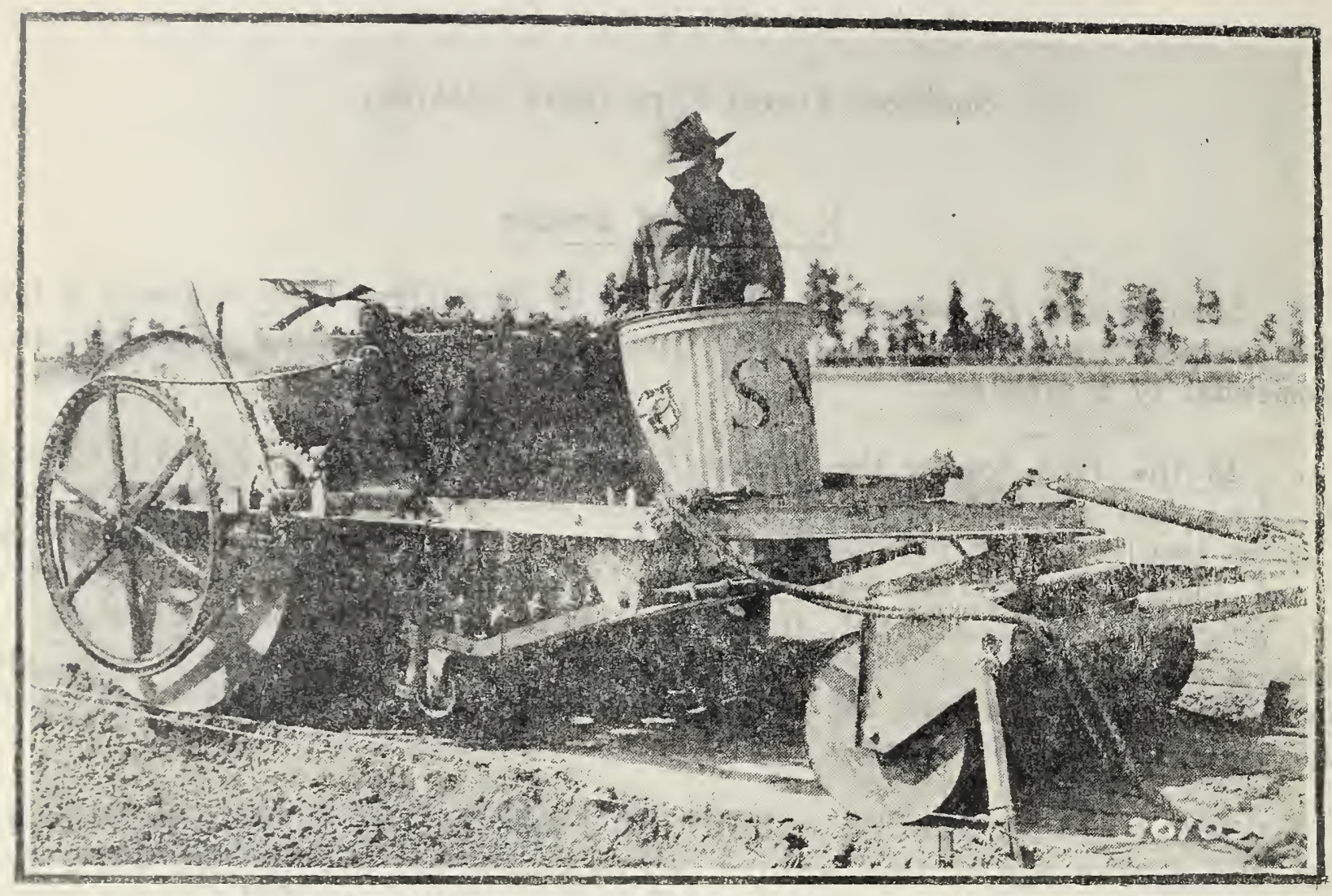

Fig. 1. The Stuart Nursery longleaf seeder. Note the intermeshing fiber gears on the seed box, and the chain running over large metal gear on the roller. The galvanized-iron can contains seed which is used to fill the seed box. The rope is used in propelling the machine. 


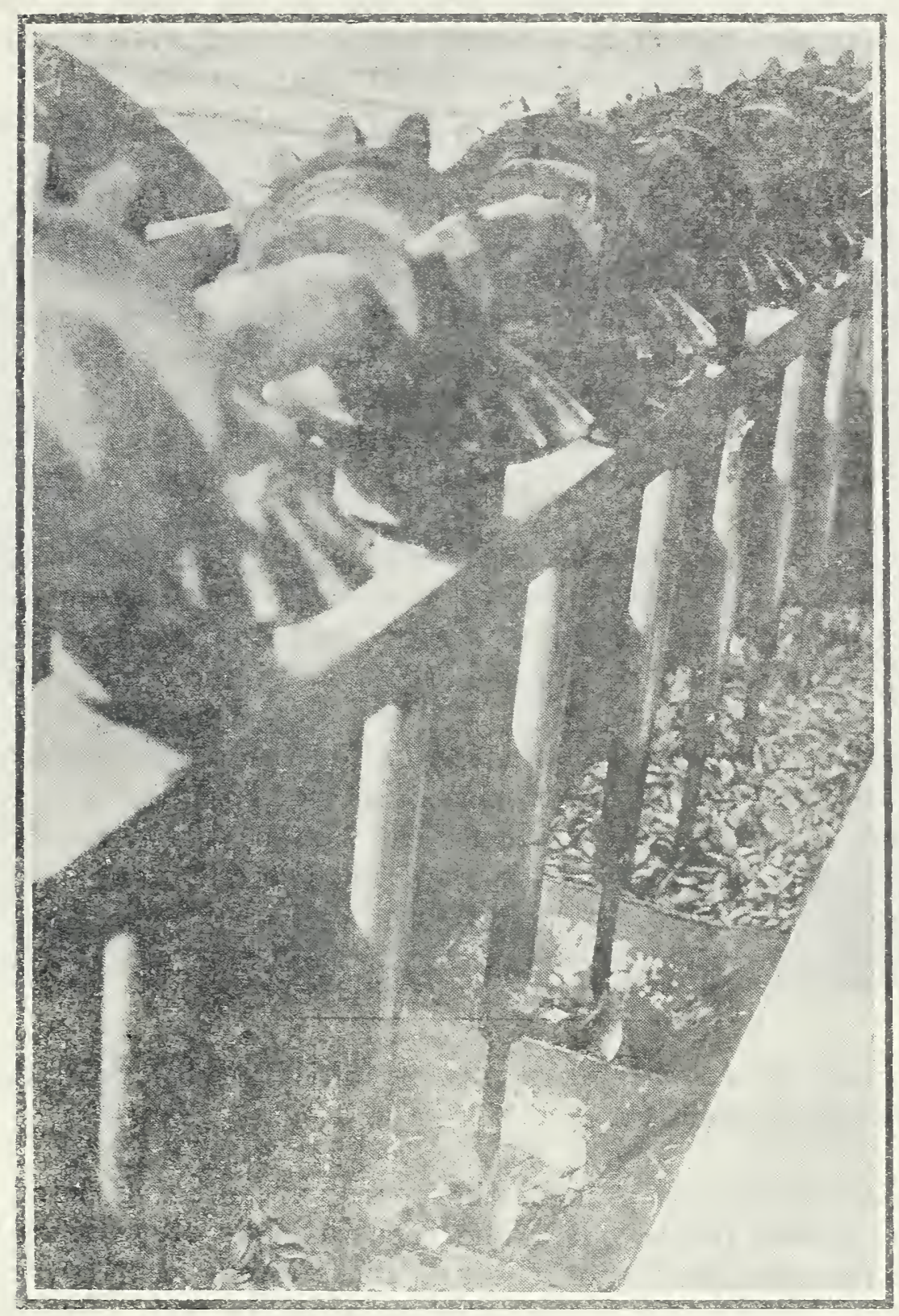

Fig. 2. - Interior of the seed box, showing the seeds in the square funnels, the drill bits fastened to the vertical shafts, and the horizontal and vertical bevel gears that cause the vertical shafts to revolve. 
this bar carried 8 similar beveled gears which meshed with the horizontal beveled gears. To this horizontal shaft, at one end, was fastened a fiber gear which meshed with a larger fiber gear fastened to the side of the seed box. This seed box with its gears was substituted for the regular seed box on the frame of the Hazard seeder. The larger fiber gear was turned by a chain which meshed with a small metal gear on the shaft of the fiber gear and a large metal gear on the roller of the machine. This large wheel was thrown into and out of gear by a lever, as on the Hazard seeder.

The mechanism described above operates in the following manner: As the seeder, propelled by 6 men, is moved forward over the bed, the large wheel is thrown into gear. The chain moves the small gear on the large fiber gear shaft, thus turning the large fiber gear. This turns the small fiber gear which causes the horizontal shaft to revolve. The 8 vertical bevel gears turn the horizontal bevel gears, thus revolving the vertical shafts to which are fastened the drill bits. As the bits revolve in the funnels, the seeds are fed along the flanges of the drill bits, through the funnels into the tubes, and to the ground in drills. (See figure 3.)

For the proper working of the machine the longleaf seed must be fairly clean, and at least partially dewinged so that only the bases of the wings are attached. The long whole wings and cone scales tend to interfere with the operation of the bits. This cleaning and dewinging are accomplished in the extractory.

This machine was used satisfactorily for the major portion of the longleaf sowing in 1935. The machine is far from perfect yet, but the Nursery staff is working on modifications to improve it. The 1936 season should see the Stuart Nursery longleaf seeder, as developed by Williamson and the Nursery staff, in first-rate working order.

\section{Continuous Dewinger}

Another contrivance which has greatly facilitated work at the Stuart Nursery is a continuous-dewinging machine.

In the seed-extraction process the cones, after being dried in the kiln, are shaken until the seed has fallen out. The seeds at this stage have their wings more or less intact. Before the seed can be sown, these wings must be removed, or in the case of longleaf pine, broken off to the smallest possible stub. During the 1934 season this dewinging was accomplished by the use of a horizontal screen-wire drum, the top half of which was hinged to the lower half so that the drum could be opened. Through the center of this drum passed a horizontal shaft which was turned by a crank on the outside of the drum. To this shaft were fastened arms which bore bristle brushes. The seed was dumped into the drum, which was then closed. The crank was turned by hand until the brushes, rubbing the seeds against the screen wire, had broken all the wings from the seeds. The dirum was then opened and the dewinged seeds scooped out. The broken wings and trash had passed through the screen, and were shoveled out from below. Although this method successfuliy dewinged the seed, it was cumbersome and very time-consuming. 


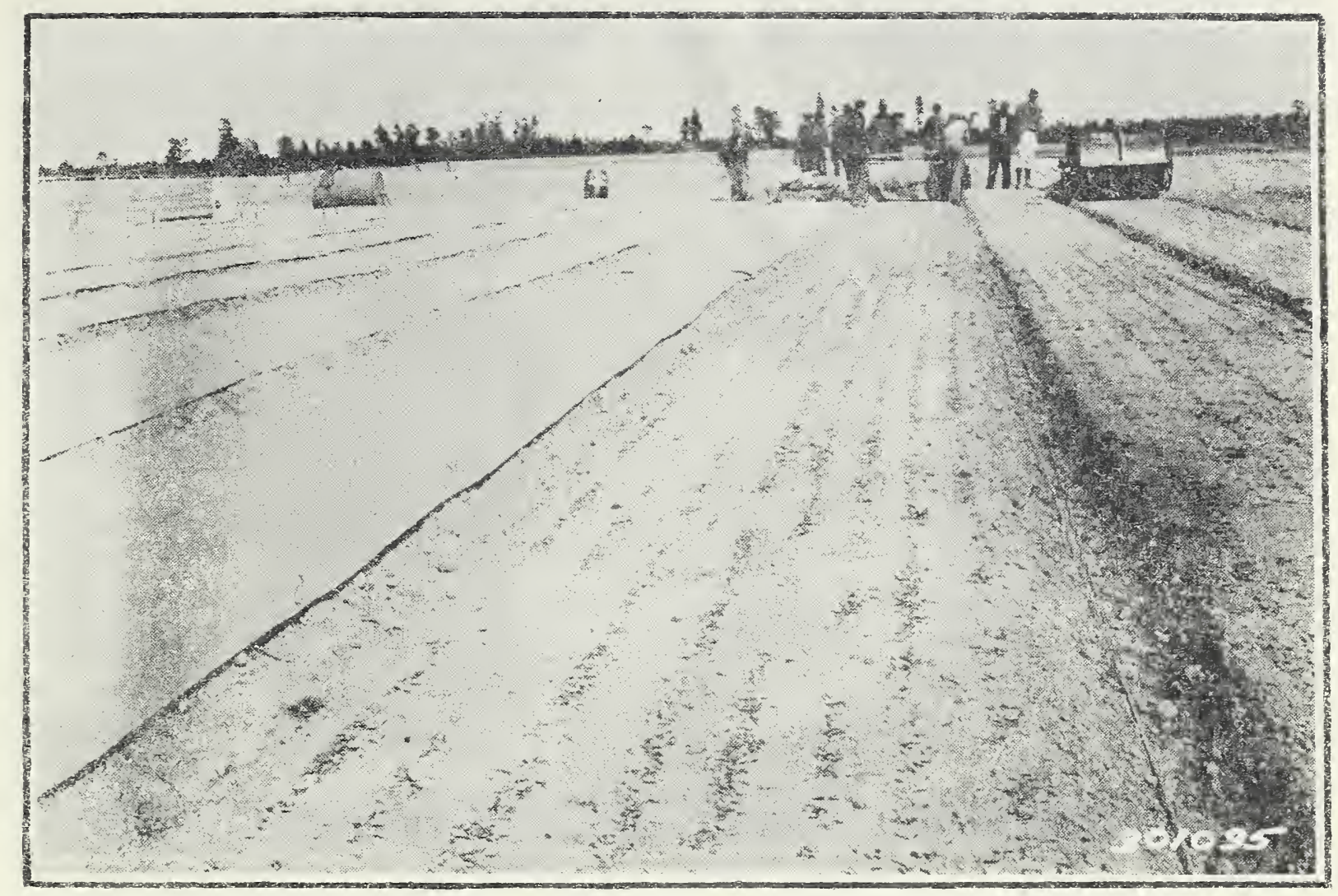

Fig. 3. - Longleaf seed in drills sown by the Stuart Nursery longleaf seeder. 


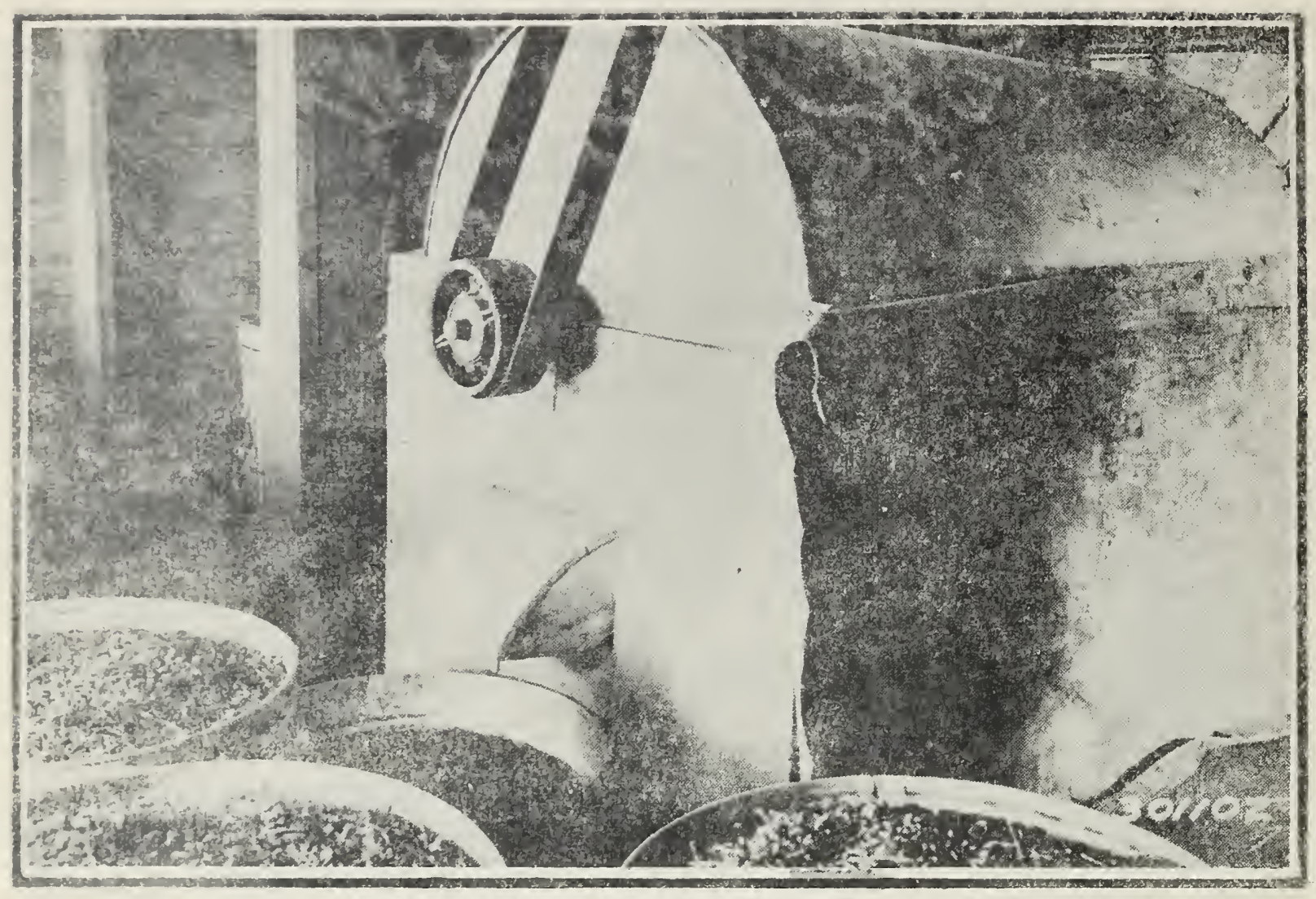

Fig. 4. - Stuart Nursery continuous dewinger. The hopper at the small end of the frustum can be seen at the right; the chute at the large end, in the lower central part of the picture. The difference in diameter of the two ends provides for sufficient slope to insure continuous passage of the seed. The galvanized iron and canvas covers were necessitated by the large quantities of dust. 
Because of the expanded production, more seeds had to be handled in less time than was possible by this method. Again part of the Stuart Nursery staff-Herbert Muntz, in charge of the extraction work, and the author--worked on possible ways of dewinging seed by a continuous process. The result was the present continuous dewinger. This consists of a frustum of a cone, made of corrugated, perforated sheet metal, and mounted with its axis horizontal. The dimensions are 66 inches long, 30 inches in diameter at the small end, and 36 inches at the large end. This axis is a shaft to which are fastened 6 sets of 3 arms each. The arms in each set are at right-angles to the horizontal shaft, and are separated from each other by angles of $120^{\circ}$. Each set of 3 is of different length, the longest at the large end of the frustum, the shortest at the small end. A bristle brush runs from each arm in the first set of 3 to the corresponding arm in the second set, so that the brushes just touch the interior periorated corrugated metal surface of the frustum. Similar brushes connect corresponding arms in the third and fourth sets and in the fifth and sixth. The shaft is turned by a fly-wheel and belt, driven from a central shaft operated by a small motor. The upper half of the frustum is hinged to permit opening and cleaning.

At the sma11 end of the frustum is the hopper into which the seed is dumped. At the larger end is the chute from which the dewinged seed emerges. As the shaft is turned the brushes rub the seed against the interior surface, breaking the wings and forcing the trash through the perforations, and carrying the seeds forward to the larger end. By the time the seeds have reached the chute they have been dewinged, and are collected in tubs to be run through the fanning mill for further cleaning. The seeds are thus dumped in one end and, by the force of the brushes and slope of the frustum, are carried out the other end in one continuous process without further handl ing.

Because of the large amounts of dust produced it was necessary to cover the dewinger with galvanized iron and canvas. Other less important modifications may also be made before the next season.

A point worth emphasizing in connection with these machines is the benefit derived from joint planning and mutual constructive criticism by several men of varied training and experience. The team work involved has clearly resulted in speed and economy in the design of apparatus adequate for the needs of the nursery. It is the purpose of this paper to make the designs of these pieces of machinery more generally available, and to stimulate a still more extensive pooling of ideas and resources. 


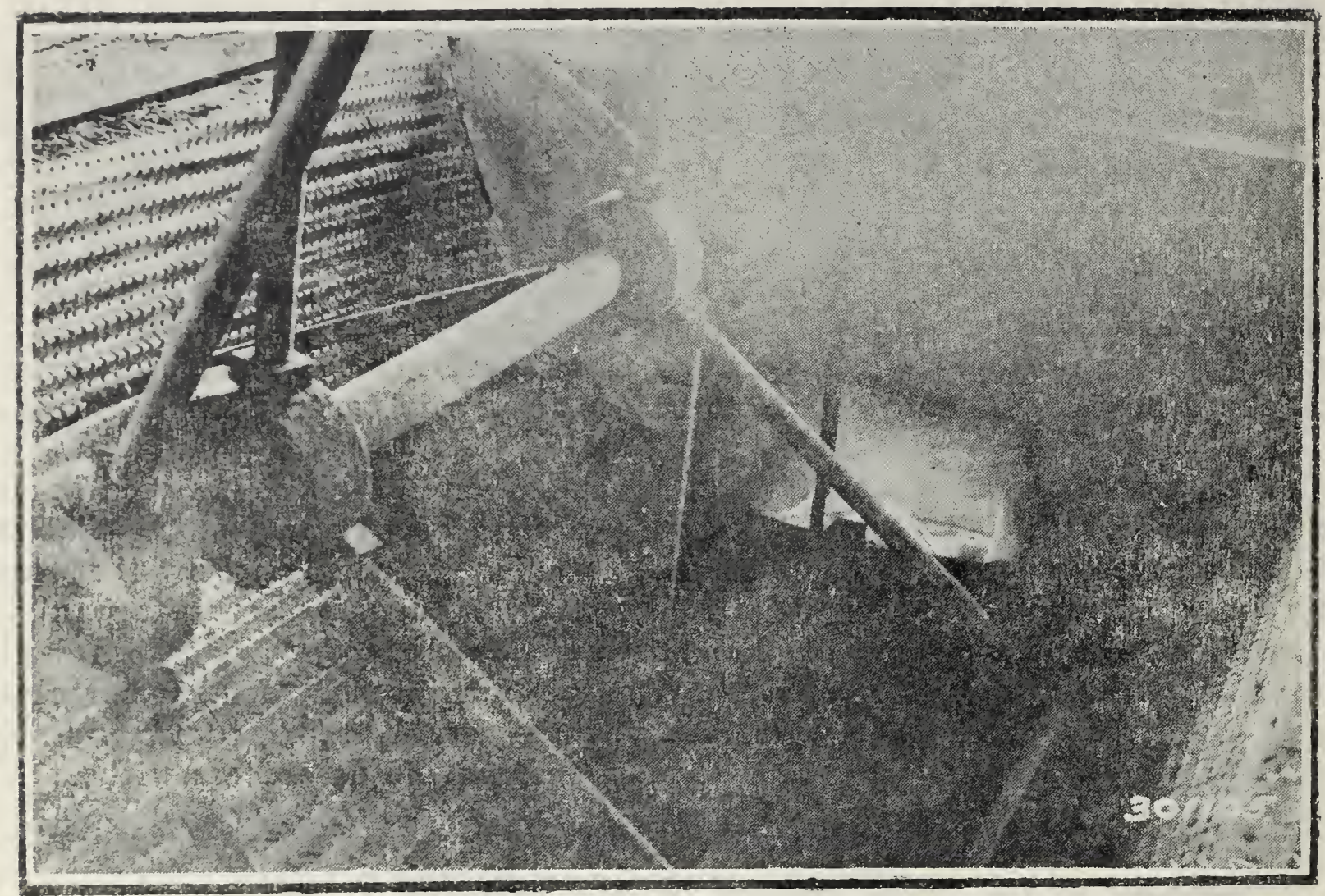

Fig. 5. - Interior view of dewinger, looking toward the chute at the larger end. Note the horizontal shaft to which are attached the vertical supports for the bristle brushes. Note also the corrugated perforated interior surface. 